\title{
4
}

\section{Qualidade físico-química e detecção de resíduos e contaminantes no mel - estudo de caso}

\author{
Ricardo Lacava Bailone ${ }^{1}$, Hirla Costa Silva Fukushima ${ }^{2}$ e Roberto de Oliveira Roça ${ }^{3}$
}

A intensificação de análises oficiais no controle de qualidade de mel por parte do Serviço de Inspeção Federal nos últimos anos possibilitou o reconhecimento do mel brasileiro no mercado internacional, tornando o Brasil um dos maiores exportadores do mundo. Neste contexto, o atual estudo reportou os parâmetros físico-químicos e detecção de resíduos e contaminantes analisados como forma de monitoramento de qualidade do mel em dois entrepostos do Estado de São Paulo. Para a realização dos ensaios adotou-se as diretrizes e métodos recomendados pelo Ministério da Agricultura para cada uma das variáveis. Com referência aos parâmetros físico-químicos, as análises mostraram que $83,3 \%$ das amostras estavam em conformidade com a legislação. Em relação às análises de resíduos e contaminantes, foram detectadas presenças de nitrofurazona (substância cancerígena) em 10,7\% das amostras, sendo que $7,14 \%$ estavam acima do permitido em legislação. Assim, observou-se que o mel atuou como marcador ambiental regional da flora circunjacente que havia sido tratada com o produto químico, o qual é tóxico e carcinogênico para humanos, representando risco à Saúde Pública. A detecção de tal composto mostra a efetividade do Programa Nacional de Controle de Resíduos e Contaminantes. Programas semelhantes devem ser adotados e aprimorados tanto no campo como no varejo para que esta detecção se faça de maneira eficiente e ostensiva.

Palavras-chave: alimento, fraude, inocuidade alimentar, monitoramento, resíduos.

\section{Physicochemical quality and detection of residues and contaminants in honey - case study}

The intensification of official analyses for quality control of honey by the Federal Inspection Service in recent years has enabled the recognition of Brazilian honey in the international market, making the country one of the largest exporters in the world. In this context, the present study reported the physicochemical parameters and detection of residues and contaminants as a way of monitoring of honey quality in two honey warehouses of São Paulo state. The tests followed the guidelines and methodologies recommended by the Ministry of Agriculture for each parameter. With respect to the physicochemical parameters, the results showed that $83.3 \%$ of the samples were in accordance with the law. The analysis of residues and contaminants evidenced the presence of nitrofurazone

${ }^{1}$ Doutorando no Programa de Pós-Graduação em Medicina Veterinária do Departamento de Saúde Animal, Saúde Pública Veterinária e Segurança Alimentar, Universidade Estadual Paulista Júlio de Mesquita Filho (UNESP) - Botucatu, SP e pela Harper Adams University, Newport, Shropshire, Inglaterra. Agente de Inspeção Sanitária e Industrial de Produtos de Origem Animal, Serviço de Inspeção Federal, Ministério da Agricultura, Pecuária e Abastecimento - São Carlos, SP. Endereço para correspondência: Rua Joaquim Vicente, 192 - Parque Industrial Antonio Guaraty, Ibaté - SP. CEP: 14815-000. E-mail: ricardo.bailone@agricultura.gov.br

${ }^{2}$ Doutora em Aquicultura, Centro de Aquicultura da Universidade Estadual Paulista (CAUNESP) - Jaboticabal, SP. Endereço para correspondência: Rua Joaquim Vicente, 192 - Paręue Industrial Antonio Guaraty, Ibaté - SP. CEP: 14815-000. E-mail. hirlafukushima@gmail.com

${ }^{3}$ Professor do Departamento de Economia, Sociologia e Tecnologia da F.C.A., Universidade Estadual Paulista Júlio de Mesquita Filho (UNESP) - Botucatu, SP. Pesquisador do CNPq. Endereço para correspondência: Rua José Barbosa de Barros n 1.780. Caixa Postal 237, Fazenda Lageado, Botucatu, SP. CEP 18610-307. E-mail. robertoroca@fca.unesp.br 
(carcinogen compound) in 10.7\% of samples, of which $7.14 \%$ were above the permitted in law. Thus, honey served as a regional environmental marker of the surrounding flora previously treated with the chemical, which is toxic and carcinogenic to humans, representing a risk to public health. The detection of this compound shows the effectiveness of the National Program of Residues and Contaminants Control. Similar programs should be adopted and improved in both the field and at retail, focused on an effective and ostensible detection.

Keywords: food, fraud, monitoring, residues, safety food.

\section{INTRODUÇÃO}

A cadeia de apicultura no Brasil encontra-se em constante desenvolvimento, sendo que, a partir do ano 2000 e decorrente da implantação do Plano Nacional de Controle de Resíduos e Contaminantes (PNCR) [1], o país iniciou a inserção desse produto no mercado internacional, ganhando rápida projeção como país exportador, alcançando a exportação de US $\$ 98,6$ milhões de mel em 2014. Tal volume fez com que o Brasil se tomasse o oitavo maior exportador de mel do mundo [2].

Consumidores em geral consideram o mel um alimento altamente saudável e inócuo devido às suas qualidades terapêuticas, tais como atividade antimicrobiana, protetor de doenças gastrointestinais, propriedades antioxidantes, propriedades prebióticas, além de ser uma boa fonte de energia [3]. Contudo, apesar das vantagens mencionadas, a apicultura brasileira com ênfase na produção de mel tem potencialidades ainda pouco exploradas, além de diversos desafios para se consolidar no mercado internacional. Adequações devem ser realizadas pelos segmentos do setor, vistoque há parâmetros estabelecidos internacionalmente e que precisam ser cumpridos pelos que almejam comercializar no mercado mundial[ [4].

A implantação do PNCR possibilitou o fim do embargo europeu ao mel brasileiro em 2007, e consequentemente, o Brasil foi o quinto maior exportador mundial de mel no primeiro semestre de 2008 [5. No âmbito de ação do Ministério da Agricultura, Pecuária e Abastecimento (MAPA), embasamentos legais, como a Portaria no 6 de 1985 [6], a Instrução Normativa no 11 de 2000 [7] e a Instrução Normativa no 10 de $2008[8]$ - parte integrante do PNCR - fixam os padrões de qualidade para o mel produzido em território nacional.
Neste contexto, o objetivo do presente estudo foi relatar os parâmetros físico-químicos e de resíduos e contaminantes presentes no mel de dois entrepostos localizados na região centro-leste do estado de São Paulo.

\section{MATERIAL E MÉTODOS}

O estudo foi conduzido em dois estabelecimentos beneficiadores de mel, situados na região centro-leste do estado de São Paulo, sob a supervisão do Serviço de Inspeção Federal. Os dados foram obtidos por meio de análises laboratoriais oficiais (parâmetros físico-químicos, resíduos e contaminantes), que fazem parte dos programas de controle do Serviço de Inspeção Federal do MAPA.

\section{Análises físico-químicas}

Foram coletadas vinte e quatro amostras de mel entre os anos de 2012 e 2014, seguindo-se os métodos descritos na Portaria no 1 de 1981 do MAPA [?] referente aos métodos analíticos para controle de produtos de origem animal para os seguintes parâmetros: umidade, $\mathrm{pH}$, acidez, índice de formol, resíduo mineral fixo, açúcares redutores, sacarose aparente, sólidos insolúveis, hidroxometilfurfural (HMF-determinação quantitativa) e prova de Lund. Conforme preconiza a legislação, estas coletas foram realizadas trimestralmente em cada estabelecimento. As análises de dados foram calculadas através de média, desvio padrão e amplitude, e comparadas com a legislação brasileira vigente. Os ensaios realizados foram:

a) Umidade: utilizou-se o método de refratometria a $20^{\circ} \mathrm{C}$ (refratômetro de Abbé com circulador de água a $20^{\circ} \mathrm{C}$ ). Interpretação realizada através da tabela de Chataway.

b) pH: pesou-se $10 \mathrm{~g}$ de mel e diluiu-se com $75 \mathrm{~mL}$ de água deionizada. Em seguida, pHgâmetro foi aferido 
Qualidade físico-química e detecção de contaminantes no mel. Bailone, Fukushima e Roça

com solução tampão pH 4,0 e realizada a leitura da amostra.

c) Acidez: titulação com $\mathrm{NaOH}$, fundamentada na neutralização de ácidos por solução de $\mathrm{NaOH}$ até $\mathrm{pH}$ 8,3 . Utilizou-se a mesma solução de mel preparada para a determinação do $\mathrm{pH}$.

d) Índice de Formol: a técnica fundamenta-se na combinação do formaldeído com os grupos amínicos dos aminoácidos, que nesta reação são titulados com $\mathrm{NaOH}$. Na mesma solução utilizada para acidez, o pH foi reduzido para 8 usando-se uma solução de ácido acético $0,1 \mathrm{~N}$. Em seguida, acrescentou-se $5 \mathrm{~mL}$ de formol a 35\% neutralizado também a $\mathrm{pH}$ 8. Após 1 minuto sob agitação, titulou-se com solução de hidróxido de sódio $0,1 \mathrm{~N}$ até $\mathrm{pH} 8$.

e) Resíduo Mineral Fixo: determinado por meio da incineração de matéria orgânica a $600^{\circ} \mathrm{C}$, sem apreciável decomposição dos constituintes do resíduo mineral ou por sua volatização. Pesou-se $2 \mathrm{~g}$ de amostra de mel e transferiu-se para cadinho previamente aquecido em forno mufla por meia hora, e em seguida esfriado em dessecador e pesado. Levou-se novamente ao forno mufla a $600^{\circ} \mathrm{C}$ e calcinou-se até cinzas brancas. Repetiuse a operação até encontrarem-se pesosconstantes.

f) Açúcares Redutores: determinado pelo método de Fehling: $2 \mathrm{~mL}$ de solução de mel a 20\% (0,4 g) foram misturados a $100 \mathrm{~mL}$ de água destilada. Em seguida realizou-se filtração em filtro seco para frasco seco, transferindo-se o filtrado para bureta de $25 \mathrm{~mL}$. Pipetouse volumetricamente $10 \mathrm{~mL}$ de cada uma das soluções de Fehling (A e B) para Erlenmeyer de $250 \mathrm{~mL}$ e adicionou-se $40 \mathrm{~mL}$ de água destilada. Em seguida, aqueceu-se até a ebulição e gotejou-se a solução da amostra até que o líquido sobrenadante ficasse levemente azulado. Mantendo-se a ebulição, adicionouse uma gota de solução de azul de metileno a $1 \%$, gotejando até descoloração do indicador para realização do cálculo através da fórmulaabaixo:

$\%$ Açúcares Redutores em Glicose $=(100 \times 100 \times \mathrm{x}) / \mathrm{VxP}$

$\mathbf{T}=$ título da solução Fehling

$\mathbf{V}=$ quantidade de $\mathrm{mL}$ de amostra gastas na titulação

$\mathbf{P}=$ peso da amostra em gramas na solução $(0,4 \mathrm{~g})$ g) Sacarose Aparente: $2 \mathrm{~mL}$ de solução de mel a $20 \%$ $(0,4 \mathrm{~g})$ foram miturados a $40-50 \mathrm{~mL}$ de água destilada e $1 \mathrm{~mL}$ de ácido clorídrico concentrado. A solução permaneceu em banho-maria a $60^{\circ} \mathrm{C}$ por 1 hora. Após esfriar, neutralizou-se com solução de hidróxido de sódio a 10\%, com auxílio de papel tomasol como indicador. Em seguida, o volume da solução foi completado até $100 \mathrm{~mL}$ com água destilada, sendo posteriormente agitado e filtrado em filtro seco para frasco seco. Logo após, transferiu-se a solução ou filtrado obtido para bureta de $25 \mathrm{~mL}$, e pipetou-se volumetricamente $10 \mathrm{~mL}$ de cada uma das soluções de Fehling (A e B) para Erlenmeyer de $250 \mathrm{~mL}$, adicionando-se em seguida $40 \mathrm{~mL}$ de água destilada. Posteriormente, aqueceu-se até a ebulição e gotejou-se a solução da amostra até que o líquido sobrenadante ficasse levemente azulado. Mantendo-se a ebulição, adicionou-se uma gota de solução de azul de metileno a $1 \%$ e continuou-se gotejando até descoloração do indicador para realização do cálculo através da fórmula abaixo:

$\%$ Glicídios totais $=(100 \times 100 \times \mathrm{T}) \mathrm{VxP}$

Sacarose aparente $=($ glicídios totais - glicídios redutores $) \times 0,95$

$\mathbf{T}=$ título da solução Fehling

$\mathbf{V}=$ quantidade de $\mathrm{mL}$ de amostra gastas na titulação

$\mathbf{P}=$ peso da amostra em gramas na solução $(0,4 \mathrm{~g})$

h) Sólidos insolúveis: Pesou-se $20 \mathrm{~g}$ de mel e diluiu-se com a mínima quantidade de água a $80^{\circ} \mathrm{C}$. Em seguida, transferiu-se para um cadinho de vidro poroso previamente tarado. Após este procedimento, lavou-se com água destilada a $80^{\circ} \mathrm{C}$ até a amostra ficar livre dos açúcares. Colocou-se o cadinho em uma estufa a $135^{\circ} \mathrm{C}$ durante 1 hora. Após esfriar, pesou-se a amostra e, por diferença do peso inicial foi calculado a porcentagem de sólidos insolúveis.

i) Hidroxometilfurfural - HMF (Determinação quantitativa): Determinado por espectofotometria, após a reação do HMF presente no mel com ácido tiobarbiturico (Reação de Winkler), que forma um composto de coloração vermelha. Para isto, $5 \mathrm{~g}$ de mel foram diluídos com $25 \mathrm{~mL}$ de água destilada. Em um tubo foi colocado $2 \mathrm{~mL}$ de solução de mel, $5 \mathrm{~mL}$ de solução de para-toluidina e $1 \mathrm{~mL}$ de solução de ácido barbitúrico. Em outro tubo (branco) colocou-se $2 \mathrm{~mL}$ 
de solução de mel, $5 \mathrm{~mL}$ de solução de para-toluidina e $1 \mathrm{~mL}$ de água destilada. A sequência da colocação dos reagentes foi realizada dentro de 2 minutos. Após 4 minutos fez-se a realização da leitura a $550 \mathrm{~nm}$. A quantidade de HMF foi calculada através da fórmula:

$$
\operatorname{HMF}\left(\frac{\mathrm{mg}}{\mathrm{kg}}\right)=\frac{190 \times \text { absorção }}{\text { Espessura da cubeta (se for diferente de } 1 \mathrm{~cm})}
$$

j) Prova de Lund: Fundamenta-se no princípio de que o ácido tânico precipita as substâncias albuminoidesque são componentes normais do mel. Em uma proveta, 10 $\mathrm{mL}$ de solução de mel a $20 \%$ foi adicionado de $5 \mathrm{~mL}$ de solução de ácido tânico a $0,5 \%$ e $40 \mathrm{~mL}$ de água destilada. Agitou-se e deixou-se em repouso por 24 horas, sendo mensurado o depósito formado ao fundo da proveta.

\section{Análise de resíduos e contaminantes}

Foram coletadas vinte e oito amostras de mel entre os anos de 2011 e 2015, sendo as análises realizadas em laboratórios oficiais do MAPA, Laboratório Nacional Agropecuário (LANAGRO). A periodicidade destas coletas, assim como a classe destes compostos dependem de sorteios oficiais realizados pelo MAPA, sendo distribuídas neste intervalo de tempo de maneira aleatória.

A Técnica de Espectrometria de Massa - Massa em Tandem (CL/EM/EM) foi utilizada para detecção de antimicrobianos, tais como Furaltadona/AMOZ, Furazolidona/AOZ, Nitrofurantoína/AHD, Nitrofurazona/SEM, Cloranfenicol, Eritromicina, Estreptomicina, Sulfadimetoxina, Sulfametazina, Sulfatiazol e Tilosina. Para detecção de outros antimicrobianos, tais como Clortetraciclina, Doxiciclina, Oxitetraciclina e Tetraciclina, foi utilizada a técnica de Cromatografia Líquida de alta Eficiência com detecção Ultravioleta (CLA/UV).

Para resíduos e contaminantes do grupo de Compostos Halogenados e Organoclorados (Aldrin, Alfa-HCH, Alfa-endosulfan, Beta-HCH, Dodecacloro, Endrin, Gama-HCH, Heptacloro, Tetradifona, Vinclozolina) do grupo dos Carbamatos (Captana, Carbofuran, Carbaril), do grupo dos Piretróides
(Criflutrina, Permetrina, Fenpropatrina, Deltametrina), do grupo dos Organofosforados (Clorpirifos, Dimetoato, Dissulfoton, Primifós-metil, Fenamifos, Parationa, Paration-Ethil, Profenofos, Terbufos), foi utilizada a técnica de Cromatografia Gasosa acoplada à Espectrometria de Massas (CG-EM).

A Espectrofotometria de Absorção Atômica (EAA) foi realizada para detecção de resíduos do grupo dos Contaminantes Inorgânicos (Arsênio, Cádmio, Chumbo).

As análises de dados foram realizadas através da detecção ou não de resíduos e contaminantes nas amostras analisadas.

\section{RESULTADOS}

\section{Parâmetros físico-químicos}

A Tabela 1 apresenta os resultados obtidos para os parâmetros físico-químicos avaliados. Das vinte e quatro amostras analisadas, cinco encontraram-se fora dos requisitos mínimos exigidos pela legislação brasileira, representando $16,7 \%$ do total, sendo os desvios nos seguintes parâmetros: umidade e açúcares redutores (uma amostra), índice de formol (uma amostra), sacarose (uma amostra) e sólidos insolúveis (umaamostra).

Em relação à umidade, a legislação prevê um máximo de $20 \mathrm{~g} / 100 \mathrm{~mL}$, observando-se que $95,8 \%$ das amostras estavam de acordo, com uma variação de 15,16-21,6g/100 mL. Para o $\mathrm{pH}$, observou-se amplitude de 3,34-4,49, onde todas as amostras analisadas enquadraram-se na legislação brasileira $(3,3-4,6)$. As análises de acidez em todas as amostras permaneceram dentro da legislação vigente $(\leq 50 \mathrm{meq} / \mathrm{kg})$, observandose variação de 16,08-48,70 meq $/ \mathrm{kg}$. O índice de formol, que deve ser superior a $4,5 \mathrm{~mL} / \mathrm{kg}$ de acordo com a legislação, apresentou amplitude de 2,5 a $10 \mathrm{~mL} / \mathrm{kg}$, apresentando 4,2\% das amostras analisadas para este parâmetro fora dos padrões prescritos pela legislação brasileira. 
Tabela 1. Parâmetros físico-químicos de análises realizadas entre 2012 e 2014.

\begin{tabular}{lrcccc}
\hline \multicolumn{1}{c}{ Parâmetros } & Média & Desvio Padrão & Amplitude & Unidade & Legislação \\
\hline Umidade & 17,53 & $\pm 1,64$ & $15,16-21,60$ & $\mathrm{~g} / 100 \mathrm{~mL}$ & $\leq 20 \mathrm{~g} / 100 \mathrm{~mL}$ \\
$\mathrm{pH}$ & 4,16 & $\pm 0,32$ & $3,34-4,49$ & adimensional & $3,3-4,6$ \\
Acidez & 27,56 & $\pm 8,71$ & $16,08-48,70$ & $\mathrm{meq} / \mathrm{kg}$ & $\leq 50 \mathrm{meq} / \mathrm{kg}$ \\
Índice de Formol & 5,38 & $\pm 2,12$ & $2,5-10,00$ & $\mathrm{~mL} / \mathrm{kg}$ & $4,5-15 \mathrm{ml} / \mathrm{kg}$ \\
Resíduos Minerais Fixos & 0,26 & $\pm 0,14$ & $0,03-0,43$ & $\mathrm{~g} / 100 \mathrm{~mL}$ & $\leq 0,6 \mathrm{~g} / 100 \mathrm{~mL}$ \\
Açúcares Redutores & 72,59 & $\pm 3,80$ & $62,5-81,03$ & $\mathrm{~g} / 100 \mathrm{~mL}$ & $\geq 65 \mathrm{~g} / 100 \mathrm{~g}$ \\
Sacarose & 1,34 & $\pm 2,02$ & $0,35-7,30$ & $\mathrm{~g} / 100 \mathrm{~mL}$ & $\leq 6 \mathrm{~g} / 100 \mathrm{~g} \mathrm{mel}$ \\
Sólidos Insolúveis & 0,15 & $\pm 0,27$ & $0,01-1,12$ & $\mathrm{~g} / 100 \mathrm{~mL}$ & $\leq 0,1 \mathrm{~g} / 100 \mathrm{~g}$ \\
HMF & 12,51 & $\pm 11,74$ & $4,21-20,81$ & $\mathrm{mg} / \mathrm{kg}$ & $\leq 60 \mathrm{meq} / \mathrm{kg}$ \\
Prova de Lund & 1,02 & $\pm 0,39$ & $0,6-2,00$ & $\mathrm{~mL}$ & $0,6-3 \mathrm{~mL}$ \\
\hline
\end{tabular}

Em relação ao resíduo mineral fixo, o qual deve ser $\leq 0,6 \mathrm{~g} / 100 \mathrm{~mL}$, observou-se variação de 0,03 $0,43 \mathrm{~g} / 100 \mathrm{~mL}$, onde todas as amostras analisadas encontraram-se dentro da legislaçãovigente.

Para os açúcares redutores, houve amplitude de 62,6-81,03 g/100 g, sendo que uma amostra apresentou índices inferiores a $65 \mathrm{~g} / 100 \mathrm{~g}(62,6 \mathrm{~g} / 100$ g), representando um desvio de $4,2 \%$ das amostras analisadas perante a legislação.

A concentração de sacarose variou de $0,35-7,3$ $\mathrm{g} / 100 \mathrm{~g}$, sendo que uma das amostras $(4,2 \%)$ apresentou valor de 7,3 g/100 g, ou seja, acima do permitido em legislação, que prescreve valor máximo de $6 \mathrm{~g} / 100 \mathrm{~g}$.

Em relação aos sólidos insolúveis, houve uma variação nas amostras de 0,01-1,12 g/100 g, sendo que uma amostra (4,2\%) apresentou valor de $1,12 \mathrm{~g} / 100 \mathrm{~g}$, ou seja, acima do permitido em legislação $(\leq 0,1 \mathrm{~g} / 100$ g).

A análise qualitativa de hidroxometilfurfural (HMF) reportou todas as amostras analisadas dentro da legislação vigente $(\leq 60 \mathrm{meq} / \mathrm{kg})$, com uma variação de 4,21 - 20,81 meq/kg, conforme Tabela 1 .
Para a prova de Lund, foi observada variação de 0,6 - 2,0 $\mathrm{mL}$ de precipitação, conforme indica a Tabela 1, onde todas as amostras analisadas comportaram-se dentro da legislação $(0,6-3 \mathrm{~mL})$.

\section{Resíduos e contaminantes}

Neste estudo, foram constatadas presença de nitrofurazona em três amostras (uma no ano de 2012 e duas no de 2013), sendo que duas delas ultrapassaram o Limite Máximo de Resíduo (LMR) permitido em legislação de $1 \mu \mathrm{g} / \mathrm{kg}$, conforme Tabela $2(20,7 \mu \mathrm{g} / \mathrm{kg}$ e $1,68 \mu \mathrm{g} / \mathrm{kg}$ ), representando $7,14 \%$ das amostras analisadas.

Já a terceira amostra, apresentou resíduo de $0,57 \mu \mathrm{g} / \mathrm{kg}$, ou seja, abaixo de $1,0 \mu \mathrm{g} / \mathrm{kg}$, contudo, mesmos em valores abaixo do LMR, sua presença foi detectada. 
Tabela 2. Resultados de análises oficiais com detecção de resíduos e contaminantes.

\begin{tabular}{c|c|c|c|c}
\hline \multirow{2}{*}{ Composto } & \multicolumn{3}{|c|}{ Ano } & \multirow{2}{*}{ Legislação } \\
\cline { 2 - 4 } & 2013 & 2013 & 2012 & $\leq 1,0 \mu \mathrm{g} / \mathrm{kg}$ \\
\hline NITROFURAZONA/SEM & $20,7 \mu \mathrm{g} / \mathrm{kg}$ & $0,57 \mu \mathrm{g} / \mathrm{kg}$ & $1,68 \mu \mathrm{g} / \mathrm{kg}$ & $\leq 1,5$ \\
\hline
\end{tabular}

\section{DISCUSSÃO}

\section{Parâmetros físico-químicos}

Análises fisico-químicas de mel contribuem na fiscalização de produtos importados e no controle da qualidade do mel produzido internamente. Seus resultados são comparados com padrões citados por órgãos oficiais internacionais ou com os estabelecidos pelo próprio país, protegendo o consumidor de adquirir um produto adulterado. As análises físico-químicas obrigatórias e complementares indicadas pela legislação brasileira para o controle de qualidade do mel (produto) são descritas pela Instrução Normativa no11 de 2000 [7] e para o controle de qualidade do mel (matéria-prima)

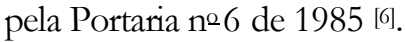

$\mathrm{Na}$ composição do mel, a água constitui o segundo componente em quantidade, geralmente variando de 15 a $21 \%$, dependendo do clima, origem floral e colheita antes da completa desidratação, sendo uma das características mais importantes por influenciar na sua viscosidade, peso específico, maturidade, cristalização, sabor, conservação e palatabilidade ${ }^{[10]}$.

Pela Instrução Normativa no 11, de 20 de outubro de 2000, do Ministério da Agricultura e Abastecimento (Regulamento Técnico de Identidade e Qualidade do Mel), o teor máximo de umidade permitido para méis de flores ou de melato é de 20 $\mathrm{g} / 100 \mathrm{~mL}$. No presente estudo, 4,2\% das amostras analisadas para este parâmetro encontraram-se fora da legislação vigente.

De acordo com Marchini et al. [11] uma das prováveis razões para valores de umidade acima do permitido, pode ser a colheita do mel oriundo de favos não operculados ou ainda período e/ou condições de armazenamento inadequadas, podendo assim, o melter absorvido umidade do ambiente. Desta forma, é importante que as condições de processamento e armazenamento das amostras sejam avaliadas, de forma a identificar a provável causa dos elevados e inadequados valores de umidade encontrados nas amostras analisadas.

A análise do $\mathrm{pH}$ mostra-se útil na avaliação da qualidade do produto [12], sendo importante por influenciar na velocidade de formação do HMF [13]. O valor de $\mathrm{pH}$ do mel pode ser influenciado pelo $\mathrm{pH}$ do néctar, solo ou associação de vegetais para composição do mel [14], sendo que substâncias presentes na mandíbula das abelhas e acrescidas durante o transporte até a colmeia podem alterar este fator [15]. A legislação brasileira estipula que este parâmetro deva apresentarse entre 3,3 a 4,6, embora esta análise seja descrita como de caráter complementar. No presente estudo, todas as amostras analisadas para este parâmetro encontraramse dentro da legislação vigente. Casos de desviopodem estar relacionados com processos fermentativos ou adulteração do produto.

A análise da acidez auxilia na avaliação do nível de deterioração do mel, indicando as condições de armazenamento e o processo de fermentação, além de contribuir para minimizar o crescimento bacteriano no produto e realçar o sabor do mesmo [16]. Deve-se à variação dos ácidos orgânicos causada pelas diferentes fontes de néctar, pela ação da enzima glicose-oxidase que origina o ácido glucônico, pela ação das bactérias durante a maturação do mel e ainda pela quantidade de minerais presentes no mel, podendo ser ainda explicada pela presença de ácidos orgânicos em equilíbrio com suas lactonas correspondentes ou ésteres internos e alguns íons inorgânicos, como fosfato [16]. A legislação aceita acidez máxima de $50 \mathrm{meq} / \mathrm{kg}$ de mel [7], sendo que no presente estudo, todas as amostras analisadas para este parâmetro apresentaram-se dentro da legislação vigente.

O índice de formol, assim como o pH, é uma avaliação de caráter complementar, contudo, constitui um parâmetro muito importante do mel por representar uma medida global dos compostos aminados, o qual permite avaliar o conteúdo de proteínas e aminoácidos, e consequentemente fornecer características que distinguem os tipos de méis entre si, 
assim como, méis falsificados [13]. A legislação prevê valor mínimo de $4,5 \mathrm{~mL} / \mathrm{kg}$. No presente estudo, uma amostra apresentou valores abaixo do prescrito em legislação $(2,5 \mathrm{~mL} / \mathrm{kg})$, representando $4,2 \%$ das amostras analisadas para este parâmetro. $\mathrm{O}$ índice de formol representa um importante indicador de adulteração, pois, quando muito baixo, pode indicar a presença de produtos artificiais, enquanto que excessivamente alto demonstra que as abelhas podem ter sido alimentadas com hidrolisado de proteínas. Nos casos onde houve desvios das amostras, os estabelecimentos foram notificados oficialmente pelo Serviço de Inspeção Federal.

O resíduo mineral fixo (teor de cinzas) expressa os minerais presentes no mel, sendo utilizado também, como um critério de avaliação de qualidade, estando diretamente relacionado com a sua origem botânica e geográfica ${ }^{[10]}$. Através de seu teor, épossível determinar algumas irregularidades no mel, como por exemplo, a falta de higiene e a não decantação e/ou filtração no final do processo de retirada do mel pelo apicultor. O máximo permitido pela legislação é de 0,6 $\mathrm{g} / 100 \mathrm{~mL}{ }^{[7}$, sendo que no atual estudo todas as amostras analisadas apresentaram-se dentro da legislação. O baixo conteúdo de cinzas em algumas amostras pode ser característico de méis florais, e a ampla faixa de valores para cinzas pode indicar ainda não uniformidade nas técnicas demanejo e/ou colheita por parte dos produtores [16]. A análise de cinzas possibilita verificar a higiene com que o mel foi manipulado, bem como a eficiência da filtração e decantação e seu grau de pureza [17] Adicionalmente, produtos com quantidades de cinzas acima do permitido podem indicar ainda elevados índices de poluição ${ }^{[18]}$.

O mel é uma solução concentrada de dois açúcares redutores: frutose e glicose, variando de 85\% a $95 \%$ da sua composição de açúcares [10]. Elevadas concentrações de diferentes tipos de açúcar são responsáveis pelas diversas propriedades físicas e químicas do mel, tais como viscosidade, densidade, higroscopicidade e capacidade de granulação (cristalização) [18]. As normas nacionais estabelecem mínimo de $65 \mathrm{~g} / 100 \mathrm{~g}[7]$ e o Codex Alimentarius de 60,0 $\mathrm{g} / 100 \mathrm{~g}$, sendo que o resultado médio obtido neste estudo estava dentro dos parâmetros exigidos em âmbito nacional e internacional, contudo, uma amostra apresentou índices inferiores a $65 \mathrm{~g} / 100 \mathrm{~g}(62,6 \mathrm{~g} / 100$ g) representando um desvio de $4,2 \%$ das amostras analisadas para este parâmetro. Esta mesma amostra também apresentou desvio perante a legislação em relação à umidade (acima de $20 \mathrm{~g} / \mathrm{mL}$ ), a qual provavelmente influenciou na menor porcentagem destes açucares redutores.

A concentração da sacarose constitui um bom critério para diferenciar os méis monoflorais dos poliflorais ${ }^{[19]}$. O teor elevado deste açúcar significa na maioria das vezes uma colheita prematura do mel, isto é, um produto em que a sacarose ainda não foi totalmente transformada em glicose e frutose pela ação da invertase [20]. A sacarose aparente para o mel floral deve ser no máximo de $6 \mathrm{~g} / 100 \mathrm{~g}$ mel [7]. O presente estudo observou variação de $0,35-7,3 \mathrm{~g} / 100 \mathrm{~g}$, sendo que uma das amostras (4,2\%) apresentou valor de 7,3 $\mathrm{g} / 100 \mathrm{~g}$ (acima do permitido em legislação). De acordo com Welke et al. [21], valores altos de sacarose, além de ser um indicativo de colheita prematura, também pode indicar adulteração pela adição deste açúcar.

Para que se obtenham padrões de qualidade mínimos para mel é necessário que o produto seja isento de substâncias estranhas de qualquer natureza, como sujidades, insetos, larvas, grãos de areia e outros. Os sólidos insolúveis correspondem aos resíduos de cera, patas e asas das abelhas, além de outros elementos inerentes do mel ou do processamento que este sofreu. Arealização desta análise permite detectar as impurezas presentes no produto, tornando-se uma importante medida de controle higiênico-sanitário [22]. O máximo de sólidos insolúveis permitido pela legislação brasileira é de $0,1 \mathrm{~g} / 100 \mathrm{~g}$ de mel, exceto para o mel prensado que se tolera até $0,5 \mathrm{~g} / 100 \mathrm{~g}$ [7]. No presente estudo, houve uma variação de $0,01-1,12 \mathrm{~g} / 100 \mathrm{~g}$, sendo que uma amostra (4,2\%) apresentou valor de 1,12 g/100 g (acima do permitido em legislação). Segundo Andrade [17], a quantidade de sólidos insolúveis é indicativa do grau de pureza auxiliando a identificar resíduo de favos e detritos da própria colmeia, e sendo assim, uma das ações corretivas poderia ser a remoção destes resíduos utilizando-se uma peneira de malha mais fina que a utilizada atualmente.

A análise de Hidroximetilfurfural (HMF) realizada por espectofotometria através da Reação de Winkler é uma prova quantitativa realizada no mel para se verificar adulteração com açúcar comercial, estocagem inadequada ou superaquecimento [23]. $\mathrm{O}$ HMF é utilizado como indicador de qualidade, uma vez que tem origem na degradação de enzimas presentes nos méis e apenas uma pequena quantidade de enzima é encontrada em méis maduros [12]. A legislação 
Qualidade físico-química e detecção de contaminantes no mel. Bailone, Fukushima e Roça

brasileira aceita no máximo $60 \mathrm{meq} / \mathrm{kg}$ de HMF no mel [7], ou seja, todas as amostras analisadas neste estudo comportaram-se dentro da legislação vigente, com uma variação de 4,21-20,81 meq $/ \mathrm{kg}$. Valores baixos de HMF são encontrados em méis recém-colhidos, contudo, valores mais elevados podem indicar alterações importantes provocadas por armazenamento prolongado em temperatura ambiente alta e/ou superaquecimento, assim como, adulterações provocadas por adição de açúcar invertido ${ }^{[12]}$.

Outra prova utilizada com o intuito de se prevenir fraudes é a prova de Lund, que indica a presença de substâncias albuminoides, componentes normais do mel e que são precipitados pelo ácido tânico adicionado na amostra. Na presença de mel natural esse precipitado forma um depósito entre 0,6 a 3,0 mL no fundo da proveta. No entanto, a reação não ocorre em mel artificial e, no caso de mel adulterado, ovolume do precipitado aparecerá em maior quantidade. De acordo com a legislação brasileira [ ${ }^{6}$ a reação de Lund deve ser positiva (precipitado entre 0,6 e $3 \mathrm{~mL}$ ). Sendo assim, todas as amostras analisadas do atual estudo comportaram-se dentro da legislação, com uma variação de $0,6-2,0 \mathrm{~mL}$.

Em relação aos parâmetros físico-químicos, observou-se que $100 \%$ das amostras apresentaram-se dentro da legislação vigente. Por outro lado, $16,7 \%$ das amostras apresentaram desvios em outros parâmetros físico-químicos analisados, demonstrando falhas durante o processo de produção.

\section{Resíduos e contaminantes}

Mel e seus derivados tem a imagem de ser um produto natural, saudável e limpo, contudo, estes produtos são produzidos no meio ambiente, poluído por diferentes fontes de contaminação, podendo atuar como marcador ambiental [24], sendo de extrema importância para os apicultores localizar e excluir as diferentes fontes de contaminação, tais como pesticidas agrícolas, contaminantes orgânicos, metais pesados, dentre outros [25]. No Brasil, medidas de intensificação na fiscalização de produtos de origem animal através de análises laboratoriais periódicas por Laboratórios Credenciados e Oficias do MAPA, assim como a implantação do PNCR, que analisa por meio de amostragem e sorteio aleatório amostras de produtos de origem animal produzidos em estabelecimentos sob a supervisão do Serviço de Inspeção Federal, tem possibilitado um avanço e melhoria na qualidade de seus produtos, assim como uma maior aceitação e respeito pelo mercado internacional e instituições de referência internacional, tais como Organização Mundial do Comércio - OMC e Food and Agriculture Organization - FAO.

Por definição, os resíduos são os princípios ativos e seus metabólitos que permanecem nos gêneros alimentares provenientes de animais que tenham sido administrados medicamentos veterinários. Os resíduos de antibióticos vulgarmente identificados no mel são tetraciclinas, sulfamidas, estreptomicina, cloranfenicol, nitrofuranos e tilosina [25], tendo origem nos tratamentos contra doenças e pragas, tanto de culturas agrícolas como da própria colmeia. De uma maneira geral, os antibióticos produzem produtos de degradação, sendo a sua detecção no mel, um indício da indevida utilização de antibióticos por parte do apicultor.

No atual estudo foram constatadas presença de nitrofurazona em três amostras nos anos de 2012 e 2013, representando $10,7 \%$ das amostras analisadas, sendo que duas delas ultrapassaram o Limite Máximo de Resíduo (LMR) permitido em legislação de $1 \mu \mathrm{g} / \mathrm{kg}$, observando-se valores de 20,7 $\mu \mathrm{g} / \mathrm{kg}$ e $1,68 \mu \mathrm{g} / \mathrm{kg}$, respectivamente, e sendo encaminhadas para $\mathrm{O}$ Subprograma de Investigação do PNCR/Mel. Totalizou-se 7,14\% das amostras fora da dos parâmetros estabelecidos pela legislação vigente, representando risco à Saúde Pública, visto que esta substância é carcinogênica. $O$ nitrofurazona é um antimicrobiano sintético, de amplo espectro, com atividade antiprotozoária, pertencente a um grupo de compostos denominados nitrofuranos, sendo uma substância cancerígena com capacidade de transformar células normais em tumorais, os quais produzem compostos de difícil eliminação e detecção, sendo de grande importância para a Saúde Pública [26]. Nos respectivos casos foi realizado o rastreamento do uso do composto químico, sendo constatada sua utilização no tratamento de doenças em plantações de eucalipto próximas a colmeia. Já a empresa produtora da terceira amostra, que apresentou resíduo de $0,57 \mu \mathrm{g} / \mathrm{kg}$, ou seja, abaixo de $1,0 \mu \mathrm{g} / \mathrm{kg}$, recebeu orientações para aadoção de medidas preventivas para evitar a violação dos limites estabelecidos oficialmente para resíduos e contaminantes.

Em outros países também se pode observar contaminação de méis pelos compostos desta mesma classe. $\mathrm{Na}$ Argentina, durante 2003 - 2004, a apicultura 
Qualidade físico-química e detecção de contaminantes no mel. Bailone, Fukushima e Roça

atravessou uma profunda crise por "nitrofuranos", e em estudos de Lanzelotti [27] foi comprovado que estes resíduos localizavam-se nos quadros que alguma vez já foram tratados diretamente com nitrofuranos em câmara de cria e nas ceras dos quadros que nunca estiveram em câmara de cria, particularmente na "borra" (proteínas). Foi observada a causa desta contaminação generalizada que se propagava pelo país por um produto que nenhum produtor registrava ter havido utilizado, constatando-se que em colmeias alguma vez tratada com nitrofurano (ainda que tenha sido realizada há anos), além de contaminar diretamente o mel, contaminava-se também a cera. Sendo assim, esta cera poderia contaminar o mel de anos posteriores, mesmo que o produtor não fizesse o uso do produto, podendo também contaminar outras colmeias não tratadas com o produto, através da cera contaminada e da transferência de núcleos.

A comercialização é uma fase delicada pela possibilidade de misturar lotes de várias origens geográficas, o que faz aumentar o risco de contaminação do mel [28]. Em diversos estudos, a detecção destes contaminantes em méis, como cloranfenicol com teores de 0,2 a $75 \not p p b^{[28,29]}$, de estreptomicina de 10 a $170 \not p b{ }^{[30]}$, de metabólitos de nitrofuranos de 5 a $25 p p b^{[31]}$ e de sulfatiazol a $600 p p b$ [32] é indicativo da complexidade destes compostos no comércio internacional. Heering et al. [33] identificaram diferentes famílias de antibióticos na mesma amostra, o que indica a possível mistura de méis de várias origens, por isso, alguns antibióticos podem servir como indicadores de sua origem geográfica, como é ocaso da estreptomicina que é usualmente utilizada na América Central e do Sul [34] e o cloranfenicol no Sudeste Asiático [28]. De acordo com Waite et al. [35] e Von Der Ohe [36], resíduos de antibióticos no mel podem ser evitados, assim como doenças apícolas podem ser controladas com sucesso sem o uso de antibióticos. De fato, experiências em diferentes países da União Europeia mostram que controle eficiente de doenças em longo prazo pode ser conduzido sem o uso destes antimicrobianos [25].

\section{CONCLUSÕES}

Observaram-se desvios nos parâmetros físicoquímicos analisados, demostrando falhas durante $\mathrm{O}$ processamento deste produto, assim como a necessidade do comprometimento eaprimoramento de produtores e beneficiadores de mel para que haja um maior controle destes parâmetros na matéria-prima e produto final.

Em relação aos resíduos e contaminantes, foram constatados índices de nitrofurazona em três amostras do produto (10,7\%), sendo que duas delas $(7,14 \%)$ apresentaram valores acima do permitido em legislação, representando risco à Saúde Pública.

O mel atuou como marcador ambiental regional da flora circunjacente a qual havia sido tratada com o produto químico, o qual é tóxico e carcinogênico para humanos. Contudo, o PNCR foi eficiente na detecção destes componentes de uso proibido ou controlado na matéria-prima, assim como, no rastreamento do composto e na orientação dos produtores em relação ao uso inadequado destes produtos químicos. Programas semelhantes devem ser adotados e aprimorados tanto no campo como no varejo para que esta detecção se faça de maneira mais eficiente e ostensiva.

\section{REFERÊNCIAS}

[1] Ministério da Agricultura, Pecuária e Abastecimento (BR). Instrução Normativa no 42, de 20 de outubro de 1999. Altera o Plano Nacional de Controle de Resíduos em produtos de origem animal - PNCR e os Programas de Controle de Resíduos em Carne - PCRC, Mel - PCRM, Leite - PCRL e Pescado - PCRP. Diário Oficial da União. 22 dez 1999; Seção $1: 213$.

[2] Brasil sobe no ranking e é o $8^{\circ}$ maior exportador de mel. Revista Globo Rural [internet] 2015 [acesso em 10 ago. 2016]. Disponível em: http:/ / revistagloborural.globo.com.

[3] Silva RA, Maia GA, Sousa PHM, Costa JMC. Composição e propriedades terapêuticas do mel de abelha. Alim Nutr. 2008;17(1):113-120.

[4] Borges JAR. Mel natural: Brasil no mercado mundial. Agroanalysis - Mercado \& Negócios.2010;30(05):13-15.

[5] Brasil foi o $5^{\circ}$ exportador mundial de mel no primeiro semestre. Revista Portuária - Economia e Negócios [internet]. 2008 [acesso em 10 jun. 2015]. Disponível em: http://www.revistaportuaria.com.br.

[6] Ministério da Agricultura, Pecuária e Abastecimento (BR). Portaria no 06, de 25 de julho de 1985. Aprova as normas higiênico-sanitárias e tecnológicas para mel, cera de abelhas e derivados, propostas pela Divisão de Inspeção de Leite e Derivados, da Secretaria de Inspeção de Produto Animal. Diário Oficial da União. 02 jul 1985; Seção 1:11100. 
Qualidade físico-química e detecção de contaminantes no mel. Bailone, Fukushima e Roça

[7] Ministério da Agricultura, Pecuária e Abastecimento (BR). Instrução Normativa no 11, de 20 de outubro de 2000. Aprova o Regulamento Técnico de Identidade e Qualidade do Mel. Diário Oficial da União. 23 out 2000; Seção 1:23.

[8] Ministério da Agricultura, Pecuária e Abastecimento (BR). Instrução Normativa no 10 de 14 de abril de2008. Aprova o Programa Nacional de Controle de Resíduos em Produtos de Origem Animal. Diário Oficial da União. 17 abr 2008; Seção 1.

[9] Brasil. Ministério da Agricultura, Pecuária e Abastecimento. Portaria no 01, de 07 de outubro de 1981. Métodos analíticos para controle de produtos de origem animal e seus ingredientes. Diário Oficial da União. 07 out 1981.

[10] Marchini LC, Geni SS, Moreti AC. Mel Brasileiro: composição e normas. Ribeirão Preto: A.S.Pinto; 2004.

[11] Marchini LC, Moreti ACCC, Otsuk IP. Análise de agrupamento, com base na composição físico-química, de amostras de méis produzidos por Apis mellifera L. no Estado de SãoPaulo. Food Sci. Technol. 2005;25(1):8-17.

[12] Silva CL, Queiroz AJM, Figueiredo RMF. Caracterização físico-química de méis produzidos no Estado do Piauí para diferentes floradas. R. Bras. Eng. Agríc. Ambiental. 2004;8(23):260-265.

[13] Crane E. O livro do mel. 2. ed. São Paulo: Nobel, 1983.

[14] Pamplona BC. Exame dos elementos químicos inorgânicos encontrados em méis brasileiros de Apis mellifera e suas relações físico-biológicas [dissertação]. São Paulo: Instituto de Biologia da Universidade de São Paulo; 1989.

[15] Evangelista-Rodrigues A, Silva SEM, Bezerra EMF. Análises físico-químicas de méis de abelhas Apis mellifera e Melipona scutellaris [internet]. [acesso em 15 nov 2003].

Disponível em: http//www.agroline.com.br/agrociencia

[16] Finola MS, Lasagno MC, Marioli J M. Microbiological and chemical characterization of honeys from Central Argentina. Food Chem. 2007;100(4):1649-1653.

[17] Andrade ECB. Análise de alimentos, uma visão química danutrição. São Paulo: Ed. Varela;2006.

[18] Abadio-Finco FDB, Moura LL, Silva IG. Propriedades físico-químicas do mel de Apis mellifern L. Food Sci. Technol. 2010;30(3):706-712.

[19] Carillo Magana FA. Meliponicultura: el mundo de las abejas nativas de Yucatán. Mérida, México;1998.
[20] Azeredo MAA, Azeredo LC, Damasceno JG. Características físico-químicas dos méis do município de São Fidélis - RJ. Food Sci. Technol.1999;19(1):3-7.

[21] Welke JE, Reginattoii S, Ferreira D, Vicenziii R, Soares JM. Caracterização físico-química de méis de Apis mellifera $\mathrm{L}$. da região noroeste do Estado do Rio Grande do Sul. Ciência Rural. 2008;38(6):1737-1741.

[22] Azeredo LC, Azeredo MAA, Souza SR, Dutra VML. Protein contents and physicochemical properties in Money simples of Apis mellifera of different origins. Food Chem. 2003;80:249-254.

[23] Evangelista-Rodrigues A, Silva EM, Beserra EMF, Rodrigues ML. Análise físico-química dos méis das abelhas Apis mellifera e Melipona scutellaris produzidos em regiões distintas no Estado da Paraíba. Ciência Rural. 2005;35(5):1166-1171.

[24] Przybylowski P, Wilczynska A. Honey as environmental marker. Food Chem. 2001;74:289-291.

[25] Bogdanov S. Contaminants of bee products. Apidologie. 2006;37:1-18.

[26] Servicio Nacional de Sanidad y Calidad Agroalimentaria. Farmacologico - Nitrofurano. Resolucion no 248/95. Buenos Aires: SENASA; 1995.

[27] Lanzelotti P. Dynamics of honey and beeswax contamination in the beehive. Case study with nitrofurans and coumaphos residues. Agro Sur.2007;25(1):28-29.

[28] Ortelli D, Edder P, Corvi C. Analysis of chloramphenicol residues in honey by liquid chromatography-tandem mass spectrometry. Chromatographia. 2004;59(1):61-64.

[29] Verzegnassi L, Royer D, Mottier P, Stadler RH. Analysis of chloramphenicol in honeys of different geographicalorigin by liquid chromatography coupled to electrospray ionization tandem mass spectrometry. Food Addit. Contam. 2003;20(4):335-342.

[30] Horie M, Saito H, Natori T, Nagata J, Nakazawa H. Determination of streptomycin and dihydro streptomycin in honey by liquid chromatography-electrospray mass spectrometry. J. Liq. Chromatogr. Relat. Technol. 2004;27(5):863-874.

[31] Khong SP, Gremaud E, Richoz J, Delatour T, Guy PA, Stadler RH, Mottier P. Analysis of matrix-bound nitrofuran residues in Worlwide-originated honeys by isotope dilution high-performance chromatography-tandem mass spectrometry. J. Agric. Food Chem.2004;52:5309-5315. 
Qualidade físico-química e detecção de contaminantes no mel. Bailone, Fukushima e Roça

[32] Kaufmann A, Roth S, Ryser B, Widmer M. Quantitative LC/MS-MS determination of sulfonamides and some other antibiotics in honey. J. AOAC Int.2002;84(4):853-860.

[33] Heering W, Usleber E, Dietrich R, Marlbauer E. Immunochemical screening for antimicrobial drug residues in commercial honey. Analyst. 1998;123:2759-2762.

[34] Edder P, Cominoli A, Corvi C. Determination of streptomycin residues in food by solid-phase extraction and liquid chromatography with post-column derivatization and fluorometric detection. J. Chromatogr. A.1999;830:345-351.
[35] Waite R, Brown M, Thompson H, Bew M. Control of American foulbrood by eradication of infected colonies. Apiacta. 2003;38:134-136.

[36] VonDer Ohe W. Control of American foulbrood by using alternatively eradication method and artificial swarms. Apiacta. 2003;38:137-139. 